\title{
Family and Caregiver Spillover Effects in Cost-Utility Analyses of Alzheimer's Disease Interventions
}

\author{
Pei-Jung Lin ${ }^{1} \cdot$ Brittany $D^{\prime} C_{r u z}{ }^{1}$. Ashley A. Leech ${ }^{1}$ Peter J. Neumann ${ }^{1} \cdot$ Myrlene Sanon Aigbogun ${ }^{2}$. \\ Dorothee Oberdhan ${ }^{2} \cdot$ Tara A. Lavelle $^{1}$
}

Published online: 22 March 2019

(c) The Author(s) 2019

\begin{abstract}
Background and objective Alzheimer's disease or dementia can impose a significant burden on family and other informal caregivers. This study investigated how the inclusion of family/informal caregiver spillover effects in a cost-utility analysis may influence the reported value of Alzheimer's disease/dementia interventions.

Methods We used PubMed to identify Alzheimer's disease or dementia cost-utility analyses published from 1 January, 2000 to 31 March, 2018. We reviewed and abstracted information from each study using a two-reader consensus process. We investigated the frequency and methods in which family/caregiver spillover costs and health effects were incorporated into cost-utility analyses, and examined how their inclusion may influence the reported incremental cost-effectiveness ratios. Results Of 63 Alzheimer's disease/dementia cost-utility analyses meeting inclusion criteria, 44 (70\%) considered at least some family/caregiver spillover costs or health effects. Thirty-two studies incorporated spillover costs only, two incorporated spillover health effects only, and ten incorporated both. The most common approach for accounting for spillover was adding informal caregiving time costs to patient costs $(n=36)$ and adding informal caregiver qualityadjusted life-years to patient values $(n=7)$. In a subset of 33 incremental cost-effectiveness ratio pairs from 19 studies, incorporating spillover outcomes made incremental cost-effectiveness ratios more favorable $(n=15 ; 45 \%)$ or kept the intervention cost saving $(n=13 ; 39 \%)$ in most cases. In fewer cases, including spillover increased incremental costeffectiveness ratios $(n=2 ; 6 \%)$, kept the intervention dominated [more costs/less quality-adjusted life-years] $(n=2$; $6 \%)$, or changed incremental cost-effectiveness ratio from dominated to less cost/less quality-adjusted life-years $(n=1$; $3 \%)$. In 11 cases (33\%), adding spillover effects into analyses resulted in a lower incremental cost-effectiveness ratio that crossed a common cost-effectiveness threshold, which could have downstream implications for programs or policies that are adopted based on cost-effectiveness analysis results.

Discussion Most Alzheimer's disease/dementia cost-utility analyses incorporated spillover costs, often as caregiver time costs, but considered spillover health impacts less often. In about $85 \%$ of the analyses, including Alzheimer's disease/dementia spillover cost or health effects decreased incremental cost-effectiveness ratios or kept the intervention cost saving. The broader value of an Alzheimer's disease/dementia intervention to society may in some cases be underestimated without considering these spillover effects on family and informal caregivers.
\end{abstract}

Electronic supplementary material The online version of this article (https://doi.org/10.1007/s40273-019-00788-3) contains supplementary material, which is available to authorized users.

Pei-Jung Lin

plin@tuftsmedicalcenter.org

1 Center for the Evaluation of Value and Risk in Health, Institute for Clinical Research and Health Policy Studies, Tufts Medical Center, 800 Washington Street, Box \#63, Boston, MA 02111, USA

2 Health Outcomes, Otsuka Pharmaceutical Development \& Commercialization, Inc., Princeton, NJ, USA 


\section{Key Points}

There is an increasing recognition of spillover effects related to informal caregiving in more recent studies that evaluate the cost effectiveness of Alzheimer's disease (AD)/dementia interventions.

Most AD/dementia cost-utility analyses incorporate spillover costs, usually as caregiver time costs, but consider spillover health impacts less often.

Incorporating $\mathrm{AD} /$ dementia family spillover costs and health effects into cost-utility analyses most often leads to more favorable cost-effectiveness ratios or keeps the intervention cost saving, compared to when spillover is not included.

\section{Introduction}

For many patients with Alzheimer's disease (AD) or dementia, the majority of care is delivered by their spouses, adult children, and other informal care providers [1-3]. Dementia and specifically AD, which accounts for $60-80 \%$ of dementia cases [4], can impose a significant financial, physical, and emotional toll on informal caregivers. In 2016, informal caregivers of people with $\mathrm{AD} /$ dementia provided an estimated 18 billion hours of unpaid assistance in USA, valued at US\$230 billion [4]. Caring for people with $\mathrm{AD} /$ dementia often involves a wide variety of tasks, ranging from personal care to home help to medication management. Approximately, one in five informal caregivers of someone with $\mathrm{AD} /$ dementia have difficulty with medical/nursing tasks, compared to one in ten non-dementia caregivers, and are more likely to report a high degree of physical and emotional strain owing to their caregiving tasks [5]. Family caregivers of people with $\mathrm{AD} /$ dementia are more likely than nondementia caregivers to help with patients' emotional or mental health problems and challenging behavioral issues [6]. As a result, $\mathrm{AD} /$ dementia caregivers may have an increased risk of anxiety, depression, and sleep disorders [3, 7-12]. Alzheimer's disease/dementia caregivers also may experience economic hardship as a result of lost work and care expenses and adverse health consequences (e.g., anxiety, depression, and disrupted sleep) [3, 7-12]. For example, national survey data indicated that employed $\mathrm{AD} /$ dementia caregivers were more likely to need to go in late or leave early, reduce their work hours because of care responsibilities, or give up working entirely, compared with non-dementia caregivers [6]. These complex caregiving situations may result in substantial cost and health "spillover effects" on family members and other informal caregivers.
Appropriate disease management can improve healthrelated quality of life and maximize function in the daily activities of $\mathrm{AD} /$ dementia patients, which may in turn alleviate caregiver burden [4]. Failing to incorporate family/ caregiver spillover outcomes in economic evaluations may underestimate the value of a healthcare intervention that may have broader benefits to society [13-16], especially in diseases associated with considerable caregiver burden, such as $\mathrm{AD} /$ dementia. Experts in the field, including the Second US Panel on Cost-Effectiveness in Health and Medicine [17, 18], have recommended that economic evaluations incorporate the full costs and benefits of healthcare interventions. Studies conducted from a societal perspective should incorporate all costs and health effects regardless of who incurs them, and regardless of whether the costs and health effects are within or outside of the health sector. In practice, cost-effectiveness studies across all diseases typically focus on outcomes of the patient alone because broader impacts related to caregiver burden can be challenging to measure and incorporate into analyses, and therefore are often omitted [14, 15]. Krol and colleagues reviewed 25 AD cost-utility analyses (CUAs) published in 2008-13 [19]. Cost-utility analyses are cost-effectiveness analyses that quantify health benefits in terms of quality-adjusted life-years (QALYs), which combine length of life and quality of life into a single metric [18]. Krol et al. found that 16 AD studies (64\%) included some costs or health effects of informal caregiving, a higher proportion than studies in rheumatoid arthritis (14\%), Parkinson's disease, (13\%) and metastatic colorectal cancer (0\%) [19]. However, it remains unclear how often the inclusion of informal caregiving costs and health effects would result in different cost-effectiveness conclusions, and have different implications for programs or policies that are adopted based on CUA results. As new interventions are developed for $\mathrm{AD} /$ dementia, it will be important to understand the economic value of these interventions, and it is important to understand whether caregiving spillover is an important component to include in CUAs.

The purpose of this study was to identify family or informal caregiver spillover effects in $\mathrm{AD} /$ dementia CUAs and examine how the inclusion of these outcomes changed CUA results. We investigated the frequency in which spillover costs (e.g., opportunity costs of caregiving time and outof-pocket payment for family or other caregivers such as transportation expenses) and spillover health impacts (e.g., subjective burden, health utility, and well-being of a family member/caregiver) have been incorporated into $\mathrm{AD} / \mathrm{demen}$ tia CUAs. Our study expanded on previous research by Krol and colleagues [19] by analyzing more AD/dementia CUAs and more recent studies, which allow us to evaluate trends in the inclusion of spillover effects in the literature. In addition, we examined how including spillover effects in a CUA may influence the reported value of $\mathrm{AD} /$ dementia care and how 
conclusions may change when spillover is included under various cost-effectiveness thresholds.

\section{Methods}

\subsection{Selection of Studies and Review Process}

We used the PubMed database to identify all available CUAs published between January 2000 and March 2018 that analyzed an intervention for a patient with AD or dementia, following the Preferred Reporting Items of Systematic Reviews and Meta-Analyses (PRISMA) protocol [20] (Fig. 1). We searched for English-language CUA articles using the following keywords: "QALYs", "quality-adjusted", "costutility analysis", "DALY", and "disability-adjusted", and identified 193 publications. We screened all abstracts and full-text articles and selected publications that contained original cost per QALY or disability-adjusted life-year (DALY) estimates. We excluded reviews, editorials, and purely methodological articles, along with economic evaluations that did not use QALYs or DALYs to quantify health benefits $(n=125)$. Because our intent was to evaluate both cost and health-related quality of life impacts on informal caregivers, we excluded economic evaluations in the form of cost per life-year gained, or other effectiveness metrics. For the purpose of studying spillover effects on informal caregivers, we selected CUAs that evaluated interventions targeting people with $\mathrm{AD} /$ dementia, and excluded studies of interventions focusing solely on caregivers $(n=5)$. This search resulted in 63 articles that met our inclusion criteria [21-83]. As a confirmation of our PubMed search, we also searched two online repositories of English-language CUAs: the Tufts Medical Center Cost-Effectiveness Analysis Registry (http://www.cearegistry.org), which includes cost per QALY studies, and the Global Health Cost-Effectiveness Analysis Registry (http://www.ghcearegistry.org), which contains cost per DALY studies. This search produced no additional articles that met our inclusion criteria.

Two independent reviewers read each of the 63 identified $\mathrm{AD} /$ dementia CUAs. We used a standardized data collection form to extract information on CUA methods and results, as well as caregiver spillover effects, which are summarized in Appendix 1. We examined a number of caregiver spillover variables, including the relationship of the caregiver to the patient, identification of spillover costs or health effects on caregivers or family members in the analysis, and method of incorporating those spillover effects into the results. Discrepancies between reviewers were resolved with a consensus audit. We conducted a pilot review of ten studies and modified the data collection form prior to reviewing the remaining 53 studies.

\subsection{Data Analysis}

We investigated the frequency in which spillover costs and health effects were considered in $\mathrm{AD} /$ dementia CUAs and summarized how they were incorporated into the analyses. We summarized the characteristics of AD/dementia CUAs with and without spillover costs or health effects. We also examined the impact of incorporating caregiver spillover effects into the reported ICERs. Specifically, when possible within a study, we compared each ICER that included family spillover costs or health effects with corresponding ICER that did not incorporate these spillover effects. Where those comparisons were not reported by the author but disaggregated costs and QALY values were, we re-calculated the ICER presented in the paper to allow this comparison. For example, if the study only reported the ICER with family spillover, and the information was available, we re-calculated the ICER without spillover. To derive patient-only costs, we subtracted caregiver costs from the total costs. To calculate patient-only QALYs, we subtracted caregiver QALYs from the total (caregiver plus patient) QALYs. We repeated these steps for the intervention and the comparator separately. We then divided the difference in patient-only costs by difference in patient-only QALYs associated with the intervention and the comparator to derive an ICER without spillover effects. We compared within-study ICER pairs with and without spillover. We recorded whether inclusion of spillover would increase, decrease, or produce no change in the ICER, and whether an ICER's increase or decrease crossed commonly cited US cost-effectiveness thresholds (i.e., cost-saving; US\$50,000-US\$150,000/QALY, and dominated; Appendix 1). All ICERs were converted to 2017 US dollars using currency exchange rates and the consumer price index.

\section{Results}

\subsection{Characteristics of Alzheimer's Disease or Dementia Cost-Utility Analyses}

All 63 identified AD/dementia CUA studies used QALYs and none used DALYs as health outcome measures. Of these, 46 focused on the Alzheimer's disease type of dementia, one on Parkinson disease-related dementia, and 16 on non-specific or other types of dementia (such as vascular dementia). Almost half of the studies $(n=31)$ evaluated the cost effectiveness of pharmaceuticals (Table 1), with donepezil being the most commonly assessed drug $(n=11)$. Most $\mathrm{AD} /$ dementia CUAs were conducted from the societal perspective $(69 \%)$, in a European country $(66 \%)$, and published between 2012 and 2018 (55\%). These 63 studies reported 127 ICERs (as some studies reported multiple ratios): 51 


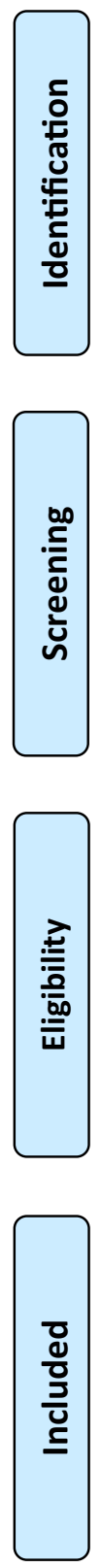

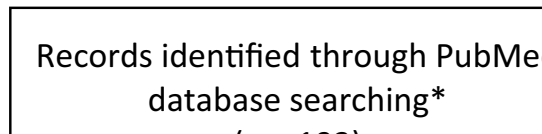

( $n=193)$
Additional records identified through the Tufts Medical

Center Cost-Effectiveness Analysis Registry or the

Global Health Cost-Effectiveness Analysis Registry $(n=0)$

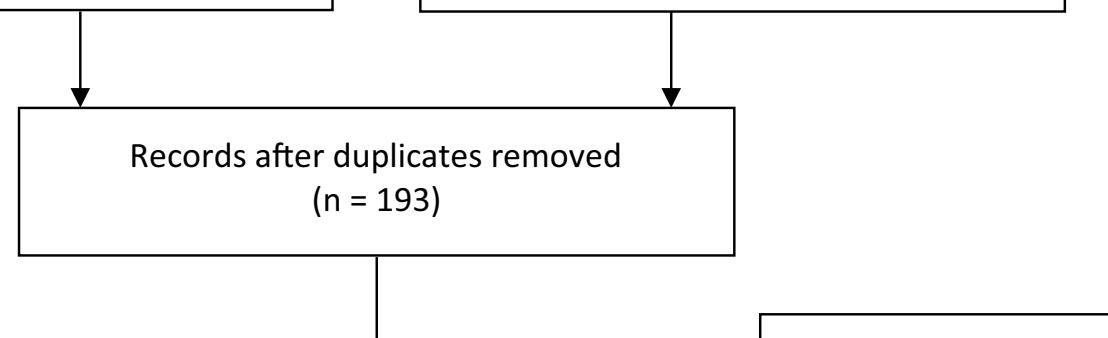

Records excluded:

Non-English language, review, editorial, methodological article, health effects not measured in QALYS or DALYS $(n=125)$

Full-text articles excluded: $A D /$ dementia CUAs of interventions focused solely on caregivers $(n=5)$

*Search terms used in the PubMed search (conducted in April 2018): ("quality adjusted life"[All Fields]

"quality adjusted life year"[All Fields] OR "quality-adjusted life-year"[All Fields] OR "quality-adjusted lifeyears"[All Fields] OR "quality adjusted life years"[All Fields] OR "per QALY gained"[All Fields]) OR ("adjusted life year"[All Fields] OR "adjusted life years"[All Fields]) OR (qaly[All Fields] OR qaly'[All Fields] OR qaly's[All Fields] OR qalys[All Fields] OR qalys/patient[All Fields] OR qalys'[All Fields]) OR ("cost utility" [All Fields] OR "cost-utility" [All Fields]) OR

(((disability-adjusted [All Fields] OR disability adjusted [All Fields] OR daly [All Fields])) NOT Daly[author]) OR (Daly [author] AND (disability-adjusted [All Fields] OR disability adjusted [All Fields]))

AND "english"[Language]

AND ("2000/01/01"[Date - Publication] : "2018/03/31"[Date - Publication])

AND (alzheimer's[Title/Abstract] OR dementia[Title/Abstract])

Fig. 1 Literature review flow diagram. AD Alzheimer's disease, CUAs cost-utility analyses, $D A L Y s$ disability-adjusted life-years, $Q A L Y s$ qualityadjusted life-years 
Table 1 Characteristics of Alzheimer's disease or dementia cost-utility analyses $(n=63$ studies)

\begin{tabular}{|c|c|c|c|}
\hline & Total & $\begin{array}{l}\text { Any spillover costs or health } \\
\text { effects, } n(\%)\end{array}$ & No spillover, $n(\%)$ \\
\hline$N(\%)$ & $63(100)$ & $44(70)$ & $19(30)$ \\
\hline \multicolumn{4}{|l|}{ Study perspective } \\
\hline Societal & 43 & $41(95)$ & $2(5)$ \\
\hline Payer & 18 & $3(17)$ & $15(83)$ \\
\hline Not stated/unknown & 2 & 0 & $2(100)$ \\
\hline \multicolumn{4}{|l|}{ Publication year } \\
\hline $2000-5$ & 10 & $3(30)$ & $7(70)$ \\
\hline $2006-11$ & 19 & $15(79)$ & $4(21)$ \\
\hline $2012-18^{\mathrm{a}}$ & 34 & $26(76)$ & $8(23)$ \\
\hline \multicolumn{4}{|l|}{ Funding source } \\
\hline Government or foundation & 32 & $21(66)$ & $11(34)$ \\
\hline Industry & 21 & $16(76)$ & $5(24)$ \\
\hline Other & 1 & $1(100)$ & 0 \\
\hline None/not determined & 9 & $6(67)$ & $3(33)$ \\
\hline \multicolumn{4}{|l|}{ Intervention type } \\
\hline Pharmaceutical & 31 & $20(65)$ & $11(35)$ \\
\hline Screening/diagnostic & 14 & $10(71)$ & $4(29)$ \\
\hline Health education or behavior & 8 & $6(75)$ & $2(25)$ \\
\hline Other & 10 & $8(80)$ & $2(20)$ \\
\hline \multicolumn{4}{|l|}{ Country } \\
\hline USA & 10 & $9(90)$ & $1(10)$ \\
\hline Europe & 41 & $27(66)$ & $14(34)$ \\
\hline Other & 12 & $8(67)$ & $4(33)$ \\
\hline \multicolumn{4}{|l|}{ Prevention stage } \\
\hline Primary/secondary & 17 & $14(82)$ & $3(18)$ \\
\hline Tertiary & 46 & $30(65)$ & $16(35)$ \\
\hline \multicolumn{4}{|l|}{ Disease stage targeted } \\
\hline Mild/moderate & 33 & $22(67)$ & $11(33)$ \\
\hline Mild/moderate/severe & 15 & $12(80)$ & $3(20)$ \\
\hline Other/not specified & 15 & $10(67)$ & $5(33)$ \\
\hline
\end{tabular}

${ }^{\mathrm{a}}$ As of 31 March, 2018

(40\%) cost saving; 48 (38\%) below US\$150,000/QALY; and $28(22 \%)$ over US\$150,000/QALY or dominated (higher costs but less effective).

\subsection{Spillover Effects Vs. Study Characteristics}

We found that $44 \mathrm{AD} /$ dementia CUAs (70\%) considered at least some family/caregiver spillover costs or health effects in the analysis (Table 1). All studies focused on informal caregivers and no studies included spillover cost or health effects on non-caregiving family members. Thirty-two studies incorporated spillover costs only, two incorporated spillover health effects only, and ten incorporated both. The following variables were associated with the inclusion of spillover effects:

Study Perspective: By definition, studies conducted from a societal perspective were more likely to include spillover effects (95\%; $n=41$ out of 43$)$, compared with studies conducted from a payer perspective $(17 \% ; n=3$ out of 18).

Time Trends: In 2000-5, 30\% of AD/dementia CUAs included spillover effects in analyses ( $n=3$ out of 10). This proportion increased to $79 \%$ among studies published from 2006 to 2011 ( $n=15$ out of 19$)$ and $76 \%$ in 2012-quarter 1 2018 ( $n=26$ out of 34$)$.

Funding Source: A higher proportion of industry-funded studies included spillover $(76 \% ; n=16$ out of 21$)$, compared with studies funded by government or foundation sources $(66 \% ; n=21$ out of 32$)$.

Intervention Type: Among studies that evaluated health education or behavior interventions, $75 \%$ included spillover effects ( $n=6$ out of 8 ), compared with $71 \%$ among studies evaluating screening or diagnostic procedures $(n=10$ out of 14$)$ and $65 \%$ among pharmaceuticals $(n=20$ out of 31$)$. 
Prevention Stage: Among articles evaluating primary (e.g., immunization or health education) or secondary prevention (e.g., screening), $82 \%$ included spillover ( $n=14$ out of 17), compared with $65 \%$ of the studies that evaluated tertiary interventions [e.g., AD medication] ( $n=30$ out of 46 ).

Country: A higher proportion of US studies considered spillover effects (90\%; $n=9$ out of 10), compared with studies from Europe $(66 \% ; n=27$ out of 41$)$ or other countries $(67 \% ; n=8$ out of 12$)$.

Disease Stage Targeted: Among studies targeting individuals with mild and moderate $\mathrm{AD} /$ dementia only, $67 \%$ included spillover effects $(n=22$ out of 33), compared with $81 \%$ among studies that also included patients in the severe disease state $(n=12$ out of 15$)$.

\subsection{Spillover Cost and Health Effects on Informal Caregivers}

Informal care may be provided by an unpaid family member or a non-family member (e.g., friend, neighbor). Of the 42 studies that included spillover costs, 16 (37\%) explicitly stated that they measured costs incurred by family caregivers, such as a spouse or a child (Table 2). The most common analytic approach to including caregiver costs into the analysis was to add informal caregiving time costs to patient costs $(n=36)$. Few studies included caregiver out-of-pocket costs in the analyses $(n=3)$.

Of the 12 studies that reported spillover health effects, nine included health utility values for the caregiver using preference-based instruments, most commonly the EQ-5D $(n=4)$ or SF-6D $(n=3)$. The other three reported summary measures of the informal caregivers' mental health, and stress, using measures that were not converted into health utilities, such as the General Health Questionnaire (GHQ28), the Relative's Stress Scale, and the Zarit Caregiver Rating Scale $[25,73,82]$. Five studies (38\%) explicitly stated the spillover health effects were on caregivers identified as family members. When caregiver health impacts were incorporated into the analysis, most studies added caregiver QALY losses to patient values for the denominator of the $\operatorname{ICER}(n=7)$.

\subsection{Impact of Spillover Effects on the Reported Incremental Cost-Effectiveness Ratios}

Among the 127 reported ICERs, 33 ICERs from 19 studies $(30 \%)$ were reported or could be calculated with and without spillover effects (Table 3). Characteristics of this study subset are similar to those of the total sample of studies with ICERs that included spillover effects (Appendix 2). In this subset of 33 pairs of ICERs, incorporating spillover cost and/or health effects decreased ICERs [making them more favorable] $(n=15 ; 45 \%)$ or kept the intervention cost
Table 2 Methods for measuring caregiver spillover costs $(n=42$ studies) and health effects $(n=12$ studies $)$

\begin{tabular}{lc}
\hline Studies including any caregiver costs $(n=42$ studies) & \\
Informal caregiver defined as a family member, $n(\%)$ & $16(37)$ \\
Spouse & $3(7)$ \\
Child & $2(5)$ \\
Other/not specified & $11(26)$ \\
Type of caregiver cost measured, $n(\%)$ & \\
Time caregiving & $36(86)$ \\
Productivity loss & $12(28)$ \\
Other time cost & $23(55)$ \\
Not specified & $1(2)$ \\
Out-of-pocket costs & $3(7)$ \\
Not specified & $10(23)$ \\
Studies including any caregiver health effects $(n=12$ studies $)$ & \\
Informal caregiver defined as a family member & $5(38)$ \\
Spouse & $3(23)$ \\
Child & $2(15)$ \\
Other/not specified & $2(15)$ \\
Type of spillover health effects measured, $n(\%)$ & \\
Health utility & $9(75)$ \\
EQ-5D & $4(33)$ \\
SF-6D & $3(25)$ \\
Health Utility Index & $1(8)$ \\
Not specified & $1(8)$ \\
Other & $3(25)$ \\
\hline
\end{tabular}

saving $(n=13 ; 39 \%)$ in most cases. In fewer cases, including spillover increased ICERs $(n=2 ; 6 \%)$, kept the intervention dominated [more costs/less QALYs] ( $n=2 ; 6 \%)$, or changed ICER from dominated to less cost/less QALYs $(n=1 ; 3 \%)$.

In this subset of 33 ICER pairs with and without spillover effects, we also examined whether these changes in ICERs crossed a common cost-effectiveness threshold, which could lead to different cost-effectiveness implications. In 11 cases (33\%), adding spillover led to a lower ICER that crossed a cost-effectiveness threshold (Table 3 ). In most of these cases $(n=7)$, the intervention cost more than the comparator without spillover, but the intervention became cost saving with the addition of spillover. In 21 cases (64\%), including spillover effects did not change the ICER enough to cross a cost-effectiveness threshold. In one case, including spillover made the $\mathrm{AD} /$ dementia intervention less favorable, starting below the US\$50,000/QALY threshold without spillover and ending up above this threshold with spillover.

\section{Discussion}

In our review of $63 \mathrm{AD}$ or dementia CUAs, $70 \%$ of studies incorporated spillover costs related to informal care, most commonly as caregiving time costs, but considered caregiver 
Table 3 Changes in cost-utility analysis value determinations when spillover is incorporated

\begin{tabular}{|c|c|}
\hline Result & Frequency \\
\hline Number of ICERs recalculated with/without spillover ${ }^{a}$ & 33 (of 127 ratios; $26 \%$ ) \\
\hline Number of studies containing recalculated ICERs & 19 (of 63 studies; $30 \%$ ) \\
\hline \multicolumn{2}{|l|}{ How adding spillover impacted ICER } \\
\hline Spillover made the ratio more favorable at: & 11 \\
\hline Cost-saving threshold ${ }^{\mathrm{b}}$ & 7 \\
\hline US\$50,000/QALY threshold ${ }^{\mathrm{b}}$ & 4 \\
\hline US\$100,000/QALY threshold ${ }^{\mathrm{b}}$ & 2 \\
\hline US\$150,000/QALY threshold ${ }^{\mathrm{b}}$ & 1 \\
\hline Spillover made the ratio less favorable at: & 1 \\
\hline Cost-saving threshold ${ }^{\mathrm{b}}$ & 0 \\
\hline US\$50,000/QALY threshold ${ }^{\mathrm{b}}$ & 1 \\
\hline US\$100,000/QALY threshold ${ }^{\mathrm{b}}$ & 0 \\
\hline US\$150,000/QALY threshold ${ }^{\mathrm{b}}$ & 0 \\
\hline Dominated threshold (less effective, more costly) & 0 \\
\hline Including spillover did not cause ratio to cross any threshold & 21 \\
\hline Kept the intervention cost saving & 13 \\
\hline Modestly decreased ICER (making the intervention more favorable) & 4 \\
\hline Modestly increased ICER (making the intervention less favorable) & 1 \\
\hline ICER remained dominated (more costs/less QALYs) & 2 \\
\hline ICER changed from dominated (more cost/less QALYs) to less cost/less QALY & 1 \\
\hline
\end{tabular}

ICER incremental cost-effectiveness ratio, $Q A L Y s$ quality-adjusted life-years

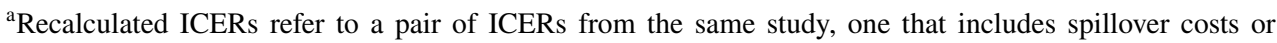
health effects and one that does not

${ }^{\mathrm{b}}$ Not mutually exclusive health impacts in analyses less often. Our findings suggest an increasing recognition of spillover effects related to informal caregiving in more recent studies that evaluate the cost effectiveness of $\mathrm{AD} / \mathrm{dem} e n t i a$ interventions. Among the $30 \%$ of studies reporting sufficient information to compare costeffectiveness ratios with and without spillover, we found that in about $85 \%$ of scenarios including spillover effects in analyses led to more favorable ICERs or kept the intervention cost saving. The broader value of an $\mathrm{AD} /$ dementia intervention to society may in some cases be underestimated without considering the cost and health impacts on informal caregivers.

Studies conducted from the societal perspective were more likely than those conducted from the payer perspective to include spillover effects, which reflects the expanded scope of these analyses. Studies published from 2006 to 2018 were more likely than those published in 2000-2005 to include spillover effects. This is consistent with an emerging international consensus on the importance of including family spillover effects in CEAs, including guidelines set forth by the Second US Panel on Cost-effectiveness in Health and Medicine [18]. Although the majority of AD/ dementia CUAs in our review targeted non-US populations, a higher proportion of US studies included spillover effects, likely because more US studies used a societal perspective
(USA: 90\%; Europe: 63\%; other: 67\%). We also found that more industry-funded studies were conducted from the societal perspective, compared with government- or foundationfunded studies ( $76 \%$ vs. $66 \%$ ), and hence were more likely to include spillover effects.

Our findings showed that spillover effects, when included in the analyses, only pertained to the primary caregiver, when in fact caregiving for someone with $\mathrm{AD} /$ dementia is typically a responsibility shared among several family members [4, 84]. Data from Spain, Sweden, Germany, the UK, and USA report that $46-92 \%$ of $\mathrm{AD} /$ dementia informal care is provided by the primary caregiver [85-87]. Future studies should measure $\mathrm{AD} /$ dementia spillover effects beyond the primary caregiver [84] and differentiate those who may experience greater cost and health impacts, such as sole caregivers compared with co-resident caregivers [87]. We also did not find any spillover effects on non-caregiving family members who also may be affected. Both populations are important to study because the spillover effects of illness may arise through both a "caregiving effect" and a "family effect", that is, the impact a family member's sickness has on someone who shares an emotional bond with that ill person $[16,88,89]$. Therefore, the AD/dementia spillover effects of studies in our review may be underestimated because of these limitations. Previous research has shown that spillover 
can be quantified in terms of health utility for more than one family member [90], and this is an important future direction for $\mathrm{AD} /$ dementia CUAs.

Most studies included caregiving time costs, with a small number stating that they valued this time as a productivity loss. Very few studies included caregiver out-of-pocket spending (such as travel expenses). In addition, our findings suggest that health-related quality-of-life spillover effects on caregivers are largely omitted in current $\mathrm{AD} /$ dementia CUAs. When spillover health effects were considered, most studies added caregiver QALY losses to patient values; a few studies reported caregiver's subjective burden but did not included the outcome in ICER calculations. These omissions are particularly striking in the context of $\mathrm{AD} /$ dementia, which has a well-known caregiving burden [1-4]. Caregivers may highly value improvements in $\mathrm{AD} /$ dementia therapy that can alleviate their burden, independent of improving the health of the patient [91]. Such treatment benefits may be particularly important because caregivers are often the ones making healthcare decisions for patients with AD/dementia. These spillover cost and health effects, when relevant, should be consistently incorporated into economic evaluations to support decision making on the value of these interventions to families and society at large.

In contrast to Krol et al.'s study that identified the inclusion of informal care in $64 \%$ of $\mathrm{AD} /$ dementia CUAs $(n=16$ out of 25 ), $70 \%$ of studies in our review ( $n=44$ out of 63 ) included at least some spillover effects. In Krol et al.'s review, the inclusion of spillover costs and health effects had limited impact on cost-effectiveness results in most studies [19]. However, based on more studies and more recent data, our findings suggest that inclusion of caregiver spillover effects in $\mathrm{AD} /$ dementia CUAs can have an impact on cost-effectiveness results. Of the 19 studies that provided sufficient information to compare cost effectiveness with and without spillover, we found that incorporating spillover effects decreased the ICERs or kept the intervention cost saving in about $85 \%$ of cases. Although this impact varied from study to study, we found that in this subset, one in three ICERs decreased to an extent that it crossed conventional CEA value thresholds, which could have downstream implications for policies adopted based on cost-effectiveness considerations. These findings emphasize the importance of including not just patient, but also caregiver outcomes in evaluating the economic value of $\mathrm{AD} /$ dementia care [13-16]. It is important to note that these findings are based on a subset of ICERs that allowed comparisons with and without spillover, but this subset was representative of the overall group of studies incorporating spillover. Consistent with our results, previous studies across a range of disease areas have reported that including spillover most commonly makes interventions appear more cost effective [90, 92]. In our review, $\mathrm{AD} /$ dementia interventions tend to alleviate caregiver burden rather than increasing caregiver involvement. Some examples include reducing symptom severity of the patient and delaying progression to more advanced disease stages, both of which can decrease caregiving time $[33,36,61]$.

There are methodological challenges in measuring AD/ dementia spillover costs and health effects. For example, commonly used preference-based measures for assessing caregiver health utility such as the EQ-5D and SF-6D cover limited mental health domains [93]. Therefore, these instruments may not be sensitive to the type of health concerns experienced by $\mathrm{AD} /$ dementia caregivers (such as stress, anxiety, and depression). In addition, as $\mathrm{AD} /$ dementia advances, the amount of time caregivers spend assisting patients with activities of daily living may increase and the health impact on the caregiver may intensify as a result of worsening patient symptoms [10, 94]. Previous studies in other disease areas have shown that caregiver spillover varies by patient symptom severity, and this level of detail should be incorporated into future $\mathrm{AD} / \mathrm{dementia}$ CEAs [95]. Indeed, we found that studies that included patients with $\mathrm{AD} /$ dementia in the severe disease state were more likely than those targeting patients with mild and moderate disease to incorporate caregiver spillover into analyses. Other spillover variation that is important to include in future studies includes changes in caregiving that occur during end-of-life care and with shifts in the patient's care setting. Caregiver burden is likely to intensify as people with $\mathrm{AD} /$ dementia approach the end of life $[4,96]$. Further, the burden of informal care may also be different when patients transition from home to a nursing facility where caregiving tasks typically shift from providing comprehensive care to emotional support, interacting with facility staff, and advocating for appropriate care [4]. Future $\mathrm{AD} /$ dementia economic analyses should better reflect the dynamic of spillover effects in relation to disease severity, end-of-life care, and care setting.

The findings from this study should be interpreted in terms of equity considerations. For instance, including family spillover may favor interventions targeted at groups that have better social support networks, or illnesses with a high family/caregiver impact (such as $\mathrm{AD} /$ dementia) as opposed to conditions that primarily impact the patient and not family members $[13,90]$. In light of these concerns, researchers have suggested that the reference case of a CUA should present aggregated results including informal care, and explore alternative spillover outcomes on family/caregivers and valuation strategies in sensitivity analyses [90, 92, 97]. Studies should also justify why (or why not) spillover effects are incorporated into analyses. This approach would promote transparency and allow decision makers to better evaluate the trade-offs [92].

Our data are limited by the information reported in the reviewed articles. In most cases, we were unable to 
determine an exact relationship between the patient and the informal caregiver unless it was clearly stated in the article. Only a subset of studies provided sufficient information for comparing the ICERs with and without spillover. The variation in the type (e.g., caregiving time, out-of-pocket costs) and the corresponding magnitude of spillover estimates included across studies also made it impossible for us to determine characteristics of studies (intervention type, funding source) where spillover was particularly important to include. Measuring the costs and health impacts related to caregiving spillover is often a time intensive process that would best be targeted to situations in which spillover is an important component to understanding the true value of an intervention. We also did not find any indication that the authors included positive spillover effects possibly related to caregivers' finding fulfillment and purpose in their responsibilities [16]. Finally, the majority of AD/dementia CUAs in our review reported cost savings or an ICER below US $\$ 150,000 / Q A L Y$, which may reflect potential publication bias (in which studies with favorable ICERs are published more often than studies with less favorable ICERs) that is found in the general CUA literature [98].

\section{Conclusion}

Our results suggest that current economic analyses that aim to measure the cost effectiveness of $\mathrm{AD} /$ dementia care largely ignore how the intervention may affect caregiver health-related quality of life, although most studies incorporate some components of informal care costs. When they are included, $\mathrm{AD} /$ dementia spillover costs and health effects tend to lead to more favorable cost-effectiveness estimates or keep the intervention cost saving. These findings indicate that the broader value of an $\mathrm{AD} /$ dementia intervention to society may in some cases be underestimated without considering caregiver cost and health outcomes.

\section{Compliance with Ethical Standards}

Funding This study was supported by research funding from Otsuka Pharmaceutical Development \& Commercialization, Inc. to Tufts Medical Center.

Conflict of interest Pei-Jung Lin has served as a consultant for Avanir, Otsuka, and Takeda outside the submitted work. Peter Neumann reports honorarium income from Merck, Bayer, Pacira, Novo Nordisk, Shire, and Amgen, other income from the Congressional Budget Office, Boston Health Economics, Vertex, and Precision Health Economics, and funding support from CEA Registry sponsors outside the submitted work. Myrlene Sanon Aigbogun and Dorothee Oberdhan are employees of Otsuka Pharmaceutical Development \& Commercialization, Inc., which provided funding for this research. Tara Lavelle has received consulting fees from Takeda Pharmaceuticals for advice on a cost-effectiveness analysis for Alzheimer's disease. Brittany D'Cruz and Ashley A. Leech have no conflicts of interest that are directly relevant to the content of this article.

Author contributions P-J L, BD'C, PJN, MSA, DO, and TAL provided the study concept and design. P-JL, BD'C, AAL, and TAL were involved in the data acquisition. P-JL, BD'C, AAL, MSA, and TAL drafted the manuscript. All authors participated in the analysis or interpretation of data as well as the preparation and critical revision of the manuscript.

Open Access This article is distributed under the terms of the Creative Commons Attribution-NonCommercial 4.0 International License (http://creativecommons.org/licenses/by-nc/4.0/), which permits any noncommercial use, distribution, and reproduction in any medium, provided you give appropriate credit to the original author(s) and the source, provide a link to the Creative Commons license, and indicate if changes were made.

\section{References}

1. Langa KM, Chernew ME, Kabeto MU, Herzog AR, Ofstedal MB, Willis RJ, et al. National estimates of the quantity and cost of informal caregiving for the elderly with dementia. J Gen Intern Med. 2001;16(11):770-8.

2. Moore MJ, Zhu CW, Clipp EC. Informal costs of dementia care: estimates from the National Longitudinal Caregiver Study. J Gerontol B Psychol Sci Soc Sci. 2001;56(4):S219-28.

3. Schulz R, Martire LM. Family caregiving of persons with dementia: prevalence, health effects, and support strategies. Am J Geriatr Psychiatry. 2004;12(3):240-9.

4. Association Alzheimer's. 2017 Alzheimer's disease facts and figures. Alzheimers Dement. 2017;13(4):325-73.

5. NAC and AARP. Caregiving in the U.S. June 2015. The National Alliance for Caregiving, Bethesda, MD and the AARP Public Policy Institute, Washington DC.

6. National Alliance for Caregiving in Partnership with the Alzheimer's Association. Dementia caregiving in the U.S. Bethesda, MD. 2017. http://www.caregiving.org/wp-content/uploa ds/2014/01/Dementia-Caregiving-in-the-US_February-2017.pdf. Accessed 3 Mar 2019.

7. Covinsky KE, Newcomer R, Fox P, Wood J, Sands L, Dane K, et al. Patient and caregiver characteristics associated with depression in caregivers of patients with dementia. J Gen Intern Med. 2003;18(12):1006-14.

8. Crespo M, Lopez J, Zarit SH. Depression and anxiety in primary caregivers: a comparative study of caregivers of demented and nondemented older persons. Int $\mathbf{J}$ Geriatr Psychiatry. 2005;20(6):591-2. https://doi.org/10.1002/gps.1321.

9. Kim Y, Schulz R. Family caregivers' strains: comparative analysis of cancer caregiving with dementia, diabetes, and frail elderly caregiving. J Aging Health. 2008;20(5):483-503. https://doi. org/10.1177/0898264308317533.

10. Mohamed S, Rosenheck R, Lyketsos CG, Schneider LS. Caregiver burden in Alzheimer disease: cross-sectional and longitudinal patient correlates. Am J Geriatr Psychiatry. 2010;18(10):917-27. https://doi.org/10.1097/JGP.0b013e3181d5745d.

11. Tremont G. Family caregiving in dementia. Med Health R I. 2011;94(2):36-8.

12. Ferrara M, Langiano E, Di Brango T, De Vito E, Di Cioccio L, Bauco C. Prevalence of stress, anxiety and depression in with Alzheimer caregivers. Health Qual Life Outcomes. 2008;6:93. https://doi.org/10.1186/1477-7525-6-93. 
13. Basu A, Meltzer D. Implications of spillover effects within the family for medical cost-effectiveness analysis. J Health Econ. 2005;24(4):751-73. https://doi.org/10.1016/j.jheal eco.2004.12.002.

14. Hoefman RJ, van Exel J, Brouwer W. How to include informal care in economic evaluations. Pharmacoeconomics. 2013;31(12):1105-19. https://doi.org/10.1007/s4027 3-013-0104-z.

15. Koopmanschap MA, van Exel JN, van den Berg B, Brouwer WB. An overview of methods and applications to value informal care in economic evaluations of healthcare. Pharmacoeconomics. 2008;26(4):269-80.

16. Wittenberg E, Prosser LA. Health as a family affair. N Engl J Med. 2016;374(19):1804-6. https://doi.org/10.1056/NEJMp 1604456.

17. Gold MRSJ, Russell LB, Weinstein MC, editors. Cost-effectiveness in health and medicine. New York: Oxford University Press; 1996.

18. Sanders GD, Neumann PJ, Basu A, Brock DW, Feeny D, Krahn $\mathrm{M}$, et al. Recommendations for conduct, methodological practices, and reporting of cost-effectiveness analyses: second panel on costeffectiveness in health and medicine. JAMA. 2016;316(10):1093103. https://doi.org/10.1001/jama.2016.12195.

19. Krol M, Papenburg J, van Exel J. Does including informal care in economic evaluations matter? A systematic review of inclusion and impact of informal care in cost-effectiveness studies. Pharmacoeconomics. 2015;33(2):123-35. https://doi.org/10.1007/s4027 3-014-0218-y.

20. Moher D, Liberati A, Tetzlaff J, Altman DG. Preferred reporting items for systematic reviews and meta-analyses: the PRISMA statement. Ann Intern Med. 2009;151(4):264-9 (W64).

21. Banerjee S, Wittenberg R. Clinical and cost effectiveness of services for early diagnosis and intervention in dementia. Int $\mathrm{J}$ Geriatr Psychiatry. 2009;24(7):748-54. https://doi.org/10.1002/ gps.2191

22. Bermingham SL. The appropriate use of neuroimaging in the diagnostic work-up of dementia: an economic literature review and cost-effectiveness analysis. Ont Health Technol Assess Ser. 2014;14(2):1-67.

23. Caro JJ, Salas M, Ward A, Getsios D, Mehnert A; AHEAD Study Group. Assessment of health economics in Alzheimer's disease. Economic analysis of galantamine, a cholinesterase inhibitor, in the treatment of patients with mild to moderate Alzheimer's disease in the Netherlands. Dement Geriatr Cogn Disord. 2002;14(2):84-9.

24. D’Amico F, Rehill A, Knapp M, Aguirre E, Donovan H, Hoare $\mathrm{Z}$, et al. Maintenance cognitive stimulation therapy: an economic evaluation within a randomized controlled trial. J Am Med Dir Assoc. 2015;16(1):63-70. https://doi.org/10.1016/j.jamda .2014.10.020.

25. D’Amico F, Rehill A, Knapp M, Lowery D, Cerga-Pashoja A, Griffin M, et al. Cost-effectiveness of exercise as a therapy for behavioural and psychological symptoms of dementia within the EVIDEM-E randomised controlled trial. Int J Geriatr Pychiatry. 2016;31(6):656-65. https://doi.org/10.1002/gps.4376.

26. Davis JC, Bryan S, Marra CA, Hsiung GY, Liu-Ambrose T. Challenges with cost-utility analyses of behavioural interventions among older adults at risk for dementia. Br J Sports Med. 2015;49(20):1343-7. https://doi.org/10.1136/bjsports-2013-09274 3.

27. Djalalov S, Yong J, Beca J, Black S, Saposnik G, Musa Z, et al. Genetic testing in combination with preventive donepezil treatment for patients with amnestic mild cognitive impairment: an exploratory economic evaluation of personalized medicine. Mol Diagn Ther. 2012;16(6):389-99. https://doi.org/10.1007/s4029 1-012-0010-7.
28. Fuh JL, Wang SJ. Cost-effectiveness analysis of donepezil for mild to moderate Alzheimer's disease in Taiwan. Int J Geriatr Psychiatry. 2008;23(1):73-8. https://doi.org/10.1002/gps.1842.

29. Gagnon M, Rive B, Hux M, Guilhaume C. Cost-effectiveness of memantine compared with standard care in moderate-to-severe Alzheimer disease in Canada. Can J Psychiatry. 2007;52(8):519 26. https://doi.org/10.1177/070674370705200810.

30. Getsios D, Blume S, Ishak KJ, Maclaine GD. Cost effectiveness of donepezil in the treatment of mild to moderate Alzheimer's disease: a UK evaluation using discrete-event simulation. Pharmacoeconomics. 2010;28(5):411-27. https://doi.org/10.2165/11531 870-000000000-00000.

31. Goldfeld KS, Hamel MB, Mitchell SL. The cost-effectiveness of the decision to hospitalize nursing home residents with advanced dementia. J Pain Symptom Manag. 2013;46(5):640-51. https:// doi.org/10.1016/j.jpainsymman.2012.11.007.

32. Green C, Picot J, Loveman E, Takeda A, Kirby J, Clegg A. Modelling the cost effectiveness of cholinesterase inhibitors in the management of mild to moderately severe Alzheimer's disease. Pharmacoeconomics. 2005;23(12):1271-82.

33. Guo S, Getsios D, Hernandez L, Cho K, Lawler E, Altincatal A, et al. Florbetaben PET in the early diagnosis of Alzheimer's disease: a discrete event simulation to explore its potential value and key data gaps. Int J Alzheimers Dis. 2012;2012:548157. https ://doi.org/10.1155/2012/548157.

34. Gustavsson A, Van Der Putt R, Jonsson L, McShane R. Economic evaluation of cholinesterase inhibitor therapy for dementia: comparison of Alzheimer's disease and dementia with Lewy bodies. Int J Geriatr Psychiatry. 2009;24(10):1072-8. https://doi. org/10.1002/gps.2223.

35. Handels RL, Joore MA, Tran-Duy A, Wimo A, Wolfs CA, Verhey FR, et al. Early cost-utility analysis of general and cerebrospinal fluid-specific Alzheimer's disease biomarkers for hypothetical disease-modifying treatment decision in mild cognitive impairment. Alzheimers Dement. 2015;11(8):896-905. https://doi. org/10.1016/j.jalz.2015.02.009.

36. Hartz S, Getsios D, Tao S, Blume S, Maclaine G. Evaluating the cost effectiveness of donepezil in the treatment of Alzheimer's disease in Germany using discrete event simulation. BMC Neurol. 2012;12:2. https://doi.org/10.1186/1471-2377-12-2.

37. Hoogveldt B, Rive B, Severens J, Maman K, Guilhaume C. Costeffectiveness analysis of memantine for moderate-to-severe Alzheimer's disease in the Netherlands. Neuropsychiatr Dis Treat. 2011;7:313-7. https://doi.org/10.2147/NDT.S19239.

38. Hornberger J, Bae J, Watson I, Johnston J, Happich M. Clinical and cost implications of amyloid beta detection with amyloid beta positron emission tomography imaging in early Alzheimer's disease: the case of florbetapir. Curr Med Res Opin. 2017;33(4):67585. https://doi.org/10.1080/03007995.2016.1277197.

39. Hornberger J, Michalopoulos S, Dai M, Andrade P, Dilla T, Happich M. Cost-effectiveness of florbetapir-PET in Alzheimer's disease: a Spanish societal perspective. J Ment Health Policy Econ. 2015;18(2):63-73.

40. Hyde C, Peters J, Bond M, Rogers G, Hoyle M, Anderson R, et al. Evolution of the evidence on the effectiveness and costeffectiveness of acetylcholinesterase inhibitors and memantine for Alzheimer's disease: systematic review and economic model. Age Ageing. 2013;42(1):14-20. https://doi.org/10.1093/ageing/afs16 5 .

41. Ikeda S, Yamada Y, Ikegami N. Economic evaluation of donepezil treatment for Alzheimer's disease in Japan. Dement Geriatr Cogn Disord. 2002;13(1):33-9.

42. Jones RW, McCrone P, Guilhaume C. Cost effectiveness of memantine in Alzheimer's disease: an analysis based on a probabilistic Markov model from a UK perspective. Drugs Aging. 2004;21(9):607-20. 
43. Jonsson L. Cost-effectiveness of memantine for moderate to severe Alzheimer's disease in Sweden. Am J Geriatr Pharmacother. 2005;3(2):77-86. https://doi.org/10.1016/j.amjop harm.2005.05.002.

44. Kasuya M, Meguro K. Health economic effect of donepezil treatment for CDR 0.5 converters to Alzheimer's disease as shown by the Markov model. Arch Gerontol Geriatr. 2010;50(3):295-9. https://doi.org/10.1016/j.archger.2009.04.014.

45. Kirbach S, Simpson K, Nietert PJ, Mintzer J. A Markov model of the cost effectiveness of olanzapine treatment for agitation and psychosis in Alzheimer's disease. Clin Drug Investig. 2008;28(5):291-303.

46. Lachaine J, Beauchemin C, Legault M, Bineau S. Economic evaluation of the impact of memantine on time to nursing home admission in the treatment of Alzheimer disease. Can J Psychiatry. 2011;56(10):596-604. https://doi.org/10.1177/070674371105601 005 .

47. Lopez-Bastida J, Hart W, Garcia-Perez L, Linertova R. Costeffectiveness of donepezil in the treatment of mild or moderate Alzheimer's disease. J Alzheimers Dis. 2009;16(2):399-407. https ://doi.org/10.3233/JAD-2009-0965.

48. MacNeil Vroomen J, Bosmans JE, Eekhout I, Joling KJ, van Mierlo LD, Meiland FJ, et al. The cost-effectiveness of two forms of case management compared to a control group for persons with dementia and their informal caregivers from a societal perspective. PLoS One. 2016;11(9):e0160908. https://doi.org/10.1371/ journal.pone.0160908.

49. Martikainen J, Valtonen H, Pirttila T. Potential cost-effectiveness of a family-based program in mild Alzheimer's disease patients. Eur J Health Econ. 2004;5(2):136-42. https://doi.org/10.1007/ s10198-003-0214-1.

50. McMahon PM, Araki SS, Neumann PJ, Harris GJ, Gazelle GS. Cost-effectiveness of functional imaging tests in the diagnosis of Alzheimer disease. Radiology. 2000;217(1):58-68. https://doi. org/10.1148/radiology.217.1.r00se1358.

51. McMahon PM, Araki SS, Sandberg EA, Neumann PJ, Gazelle GS. Cost-effectiveness of PET in the diagnosis of Alzheimer disease. Radiology. 2003;228(2):515-22. https://doi.org/10.1148/radio 1.2282020915 .

52. Meeuwsen E, Melis R, van der Aa G, Goluke-Willemse G, de Leest B, van Raak F, et al. Cost-effectiveness of one year dementia follow-up care by memory clinics or general practitioners: economic evaluation of a randomised controlled trial. PLoS One. 2013;8(11):e79797. https://doi.org/10.1371/journal.pone.00797 97.

53. Mirsaeedi-Farahani K, Halpern $\mathrm{CH}$, Baltuch GH, Wolk DA, Stein SC. Deep brain stimulation for Alzheimer disease: a decision and cost-effectiveness analysis. J Neurol. 2015;262(5):1191-7. https ://doi.org/10.1007/s00415-015-7688-5.

54. Nagy B, Brennan A, Brandtmuller A, Thomas SK, Sullivan $\mathrm{SD}$, Akehurst R. Assessing the cost-effectiveness of the rivastigmine transdermal patch for Alzheimer's disease in the UK using MMSE- and ADL-based models. Int J Geriatr Psychiatry. 2011;26(5):483-94. https://doi.org/10.1002/gps.2551.

55. Payne K, Davies LM, Noyce PR, Weiss MC. The value of the managed entry of new drugs: a case study of donepezil. Int $\mathrm{J}$ Technol Assess Health Care. 2003;19(1):114-28.

56. Peters JL, Anderson R, Hoyle M, Hyde C. Evolution of a costutility model of donepezil for Alzheimer's disease. Int J Technol Assess Health Care. 2013;29(2):147-54. https://doi.org/10.1017/ S026646231300007X.

57. Pfeil AM, Kressig RW, Szucs TD. Alzheimer's dementia: budget impact and cost-utility analysis of a combination treatment of a cholinesterase inhibitor and memantine in Switzerland. Swiss Med Wkly. 2012;142:w13676. https://doi.org/10.4414/ smw.2012.13676.
58. Rive B, Aarsland D, Grishchenko M, Cochran J, Lamure M, Toumi M. Cost-effectiveness of memantine in moderate and severe Alzheimer's disease in Norway. Int J Geriatr Psychiatry. 2012;27(6):573-82. https://doi.org/10.1002/gps.2755.

59. Rive B, Grishchenko M, Guilhaume-Goulant C, Katona C, Livingston G, Lamure M, et al. Cost effectiveness of memantine in Alzheimer's disease in the UK. J Med Econ. 2010;13(2):371-80. https://doi.org/10.3111/13696998.2010.491347.

60. Romeo R, Knapp M, Hellier J, Dewey M, Ballard C, Baldwin $\mathrm{R}$, et al. Cost-effectiveness analyses for mirtazapine and sertraline in dementia: randomised controlled trial. Br J Psychiatry. 2013;202:121-8. https://doi.org/10.1192/bjp.bp.112.115212.

61. Saint-Laurent Thibault C, Ozer Stillman I, Chen S, Getsios D, Proskorovsky I, Hernandez L, et al. Cost-utility analysis of memantine extended release added to cholinesterase inhibitors compared to cholinesterase inhibitor monotherapy for the treatment of moderate-to-severe dementia of the Alzheimer's type in the US. J Med Econ. 2015;18(11):930-43. https://doi. org/10.3111/13696998.2015.1063501.

62. Skoldunger A, Johnell K, Winblad B, Wimo A. Mortality and treatment costs have a great impact on the cost-effectiveness of disease modifying treatment in Alzheimer's disease: a simulation study. Curr Alzheimer Res. 2013;10(2):207-16.

63. Sogaard R, Sorensen J, Waldorff FB, Eckermann A, Buss DV, Phung KT, et al. Early psychosocial intervention in Alzheimer's disease: cost utility evaluation alongside the Danish Alzheimer's Intervention Study (DAISY). BMJ Open. 2014;4(1):e004105. https://doi.org/10.1136/bmjopen-2013-004105.

64. Suh GH. Modeling the cost-effectiveness of galantamine for mild to moderately severe Alzheimer's disease in Korea. Value Health. 2009;12(Suppl. 3):S49-54. https://doi.org/10.111 $1 / \mathrm{j} .1524-4733.2009 .00627 . x$.

65. Tanajewski L, Franklin M, Gkountouras G, Berdunov V, Harwood RH, Goldberg SE, et al. Economic evaluation of a general hospital unit for older people with delirium and dementia (TEAM randomised controlled trial). PLoS One. 2015;10(12):e0140662. https://doi.org/10.1371/journal.pone.0140662.

66. Teipel SJ, Ewers M, Reisig V, Schweikert B, Hampel H, Happich M. Long-term cost-effectiveness of donepezil for the treatment of Alzheimer's disease. Eur Arch Psychiatry Clin Neurosci. 2007;257(6):330-6. https://doi.org/10.1007/s00406-007-0727-1.

67. Tong T, Thokala P, McMillan B, Ghosh R, Brazier J. Cost effectiveness of using cognitive screening tests for detecting dementia and mild cognitive impairment in primary care. Int J Geriatr Psychiatry. 2017;32(12):1392-400. https://doi.org/10.1002/gps.4626.

68. Touchon J, Lachaine J, Beauchemin C, Granghaud A, Rive B, Bineau $\mathrm{S}$. The impact of memantine in combination with acetylcholinesterase inhibitors on admission of patients with Alzheimer's disease to nursing homes: cost-effectiveness analysis in France. Eur J Health Econ. 2014;15(8):791-800. https://doi. org/10.1007/s10198-013-0523-y.

69. Ward A, Caro JJ, Getsios D, Ishak K, O’Brien J, Bullock R, et al. Assessment of health economics in Alzheimer's disease (AHEAD): treatment with galantamine in the UK. Int J Geriatr Psychiatry. 2003;18(8):740-7. https://doi.org/10.1002/gps.919.

70. Weycker D, Taneja C, Edelsberg J, Erder MH, Schmitt FA, Setyawan J, et al. Cost-effectiveness of memantine in moderate-tosevere Alzheimer's disease patients receiving donepezil. Curr Med Res Opin. 2007;23(5):1187-97. https://doi.org/10.1185/03007 9907X188071.

71. Willan AR, Goeree R, Pullenayegum EM, McBurney C, Blackhouse G. Economic evaluation of rivastigmine in patients with Parkinson's disease dementia. Pharmacoeconomics. 2006;24(1):93-106.

72. Wolfs CA, Dirksen CD, Kessels A, Severens JL, Verhey FR. Economic evaluation of an integrated diagnostic approach for 
psychogeriatric patients: results of a randomized controlled trial. Arch Gen Psychiatry. 2009;66(3):313-23. https://doi.org/10.1001/ archgenpsychiatry.2008.544.

73. Woods RT, Orrell M, Bruce E, Edwards RT, Hoare Z, Hounsome B, et al. REMCARE: pragmatic multi-centre randomised trial of reminiscence groups for people with dementia and their family carers: effectiveness and economic analysis. PLoS One. 2016;11(4):e0152843. https://doi.org/10.1371/journal.pone.01528 43.

74. Yang KC, Chen HH. Probabilistic cost-effectiveness analysis of vaccination for mild or moderate Alzheimer's disease. Curr Alzheimer Res. 2016;13(7):809-16.

75. Yu SY, Lee TJ, Jang SH, Han JW, Kim TH, Kim KW. Costeffectiveness of nationwide opportunistic screening program for dementia in South Korea. J Alzheimers Dis. 2015;44(1):195-204. https://doi.org/10.3233/JAD-141632.

76. Zhang Y, Kivipelto M, Solomon A, Wimo A. Cost-effectiveness of a health intervention program with risk reductions for getting demented: results of a Markov model in a Swedish/Finnish setting. J Alzheimers Dis. 2011;26(4):735-44. https://doi.org/10.3233/ JAD-2011-110065.

77. Zwijsen SA, Bosmans JE, Gerritsen DL, Pot AM, Hertogh CM, Smalbrugge M. The cost-effectiveness of grip on challenging behaviour: an economic evaluation of a care programme for managing challenging behaviour. Int J Geriatr Psychiatry. 2016;31(6):567-74. https://doi.org/10.1002/gps.4360.

78. Brown H, D’Amico F, Knapp M, Orrell M, Rehill A, Vale L, et al. A cost effectiveness analysis of maintenance cognitive stimulation therapy (MCST) for people with dementia: examining the influence of cognitive ability and living arrangements. Aging Ment Health. 2018:1-6. https://doi.org/10.1080/13607863.2018.14424 10.

79. Gomes M, Pennington M, Wittenberg R, Knapp M, Black N, Smith S. Cost-effectiveness of memory assessment services for the diagnosis and early support of patients with dementia in England. J Health Serv Res Policy. 2017;22(4):226-35. https://doi. org/10.1177/1355819617714816.

80. Handels RLH, Wimo A, Dodel R, Kramberger MG, Visser PJ, Molinuevo JL, et al. Cost-utility of using Alzheimer's disease biomarkers in cerebrospinal fluid to predict progression from mild cognitive impairment to dementia. J Alzheimers Dis. 2017;60(4):1477-87. https://doi.org/10.3233/jad-170324.

81. Lee SA, Sposato LA, Hachinski V, Cipriano LE. Cost-effectiveness of cerebrospinal biomarkers for the diagnosis of Alzheimer's disease. Alzheimers Res Ther. 2017;9(1):18. https://doi. org/10.1186/s13195-017-0243-0.

82. Saxena N, George PP, Teo KW, Tan WS, Ng C, Heng BH, et al. Evaluation of an integrated primary care-led dementia shared care program in Singapore: an effectiveness and cost-effectiveness study. Geriatr Gerontol Int. 2018;18(3):479-86. https://doi. org/10.1111/ggi.13196.

83. Sopina E, Sorensen J, Beyer N, Hasselbalch SG, Waldemar G. Cost-effectiveness of a randomised trial of physical activity in Alzheimer's disease: a secondary analysis exploring patient and proxy-reported health-related quality of life measures in Denmark. BMJ Open. 2017;7(6):e015217. https://doi.org/10.1136/bmjop en-2016-015217.

84. Wimo A, Gustavsson A, Jonsson L, Winblad B, Hsu MA, Gannon B. Application of resource utilization in dementia (RUD) instrument in a global setting. Alzheimers Dement. 2013;9(4):429-35. e17. https://doi.org/10.1016/j.jalz.2012.06.008.
85. Bergvall N, Brinck P, Eek D, Gustavsson A, Wimo A, Winblad B, et al. Relative importance of patient disease indicators on informal care and caregiver burden in Alzheimer's disease. Int Psychogeriatr. 2011;23(1):73-85. https://doi.org/10.1017/s10416102100007 85.

86. Neubauer S, Holle R, Menn P, Grossfeld-Schmitz M, Graesel E. Measurement of informal care time in a study of patients with dementia. Int Psychogeriatr. 2008;20(6):1160-76. https://doi. org/10.1017/s1041610208007564.

87. NAC. Alzheimer's caregiving in the U.S. 2009. National Alliance for Caregiving, Bethesda, MD.

88. Bobinac A, van Exel NJ, Rutten FF, Brouwer WB. Health effects in significant others: separating family and care-giving effects. Med Decis Mak. 2011;31(2):292-8. https://doi.org/10.1177/02729 89x10374212.

89. Lavelle TA, Wittenberg E, Lamarand K, Prosser LA. Variation in the spillover effects of illness on parents, spouses, and children of the chronically ill. Appl Health Econ Health Policy. 2014;12(2):117-24. https://doi.org/10.1007/s40258-014-0079-8.

90. Al-Janabi H, Van Exel J, Brouwer W, Trotter C, Glennie L, Hannigan L, et al. Measuring health spillovers for economic evaluation: a case study in meningitis. Health Econ. 2016;25(12):1529-44. https://doi.org/10.1002/hec.3259.

91. Reed C, Belger M, Dell'agnello G, Wimo A, Argimon JM, Bruno G, et al. Caregiver burden in Alzheimer's disease: differential associations in adult-child and spousal caregivers in the GERAS observational study. Dement Geriatr Cogn Dis Extra. 2014;4(1):51-64. https://doi.org/10.1159/000358234.

92. Goodrich K, Kaambwa B, Al-Janabi H. The inclusion of informal care in applied economic evaluation: a review. Value Health. 2012;15(6):975-81. https://doi.org/10.1016/j.jval.2012.05.009.

93. Brazier J, Connell J, Papaioannou D, Mukuria C, Mulhern B, Peasgood T, et al. A systematic review, psychometric analysis and qualitative assessment of generic preference-based measures of health in mental health populations and the estimation of mapping functions from widely used specific measures. Health Technol Assess. 2014;18(34):vii-viii, xiii-xxv, 1-188. https://doi. org/10.3310/hta18340.

94. Zhu CW, Leibman C, McLaughlin T, Scarmeas N, Albert $\mathrm{M}$, Brandt $\mathrm{J}$, et al. The effects of patient function and dependence on costs of care in Alzheimer's disease. J Am Geriatr Soc. 2008;56(8):1497-503. https://doi.org/10.111 1/j.1532-5415.2008.01798.x.

95. Lavelle TA, Kent DM, Lundquist CM, Thorat T, Cohen JT, Wong JB, et al. Patient variability seldom assessed in cost-effectiveness studies. Med Decis Mak. 2018;38(4):487-94. https://doi. org/10.1177/0272989x17746989.

96. Schulz R, Mendelsohn AB, Haley WE, Mahoney D, Allen RS, Zhang S, et al. End-of-life care and the effects of bereavement on family caregivers of persons with dementia. N Engl J Med. 2003;349(20):1936-42. https://doi.org/10.1056/NEJMsa035373.

97. Brouwer WB, van Exel NJ, Koopmanschap MA, Rutten FF. The valuation of informal care in economic appraisal: a consideration of individual choice and societal costs of time. Int J Technol Assess Health Care. 1999;15(1):147-60.

98. Neumann PJ, Thorat T, Shi J, Saret CJ, Cohen JT. The changing face of the cost-utility literature, 1990-2012. Value Health. 2015;18(2):271-7. https://doi.org/10.1016/j.jval.2014.12.002. 